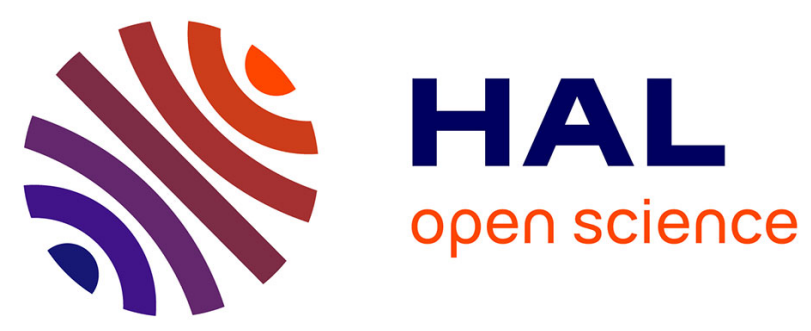

\title{
Relativistic four- and two-component calculations of parity violation effects in chiral tungsten molecules of the form NWXYZ (X, Y, Z = H, F, Cl, Br, or I).
}

Detlev Figgen, Trond Saue, Peter Schwerdtfeger

\section{To cite this version:}

Detlev Figgen, Trond Saue, Peter Schwerdtfeger. Relativistic four- and two-component calculations of parity violation effects in chiral tungsten molecules of the form NWXYZ (X, Y, Z = H, F, Cl, Br, or I).. Journal of Chemical Physics, 2010, 132 (23), pp.234310. 10.1063/1.3439692 . hal-00760983

\section{HAL Id: hal-00760983 \\ https://hal.science/hal-00760983}

Submitted on 21 Jan 2020

HAL is a multi-disciplinary open access archive for the deposit and dissemination of scientific research documents, whether they are published or not. The documents may come from teaching and research institutions in France or abroad, or from public or private research centers.
L'archive ouverte pluridisciplinaire HAL, est destinée au dépôt et à la diffusion de documents scientifiques de niveau recherche, publiés ou non, émanant des établissements d'enseignement et de recherche français ou étrangers, des laboratoires publics ou privés. 


\section{AIP $\begin{gathered}\text { mosoumator } \\ \text { chemical Physics }\end{gathered}$}

Relativistic four- and two-component calculations of parity violation effects in chiral tungsten molecules of the form NWXYZ (X, Y, Z = H, F, Cl, Br, or I)

Detlev Figgen, Trond Saue, and Peter Schwerdtfeger

Citation: J. Chem. Phys. 132, 234310 (2010); doi: 10.1063/1.3439692

View online: http://dx.doi.org/10.1063/1.3439692

View Table of Contents: http://jcp.aip.org/resource/1/JCPSA6/v132/i23

Published by the American Institute of Physics.

Additional information on J. Chem. Phys.

Journal Homepage: http://jcp.aip.org/

Journal Information: http://jcp.aip.org/about/about_the_journal

Top downloads: http://jcp.aip.org/features/most_downloaded

Information for Authors: http://jcp.aip.org/authors

\section{ADVERTISEMENT}

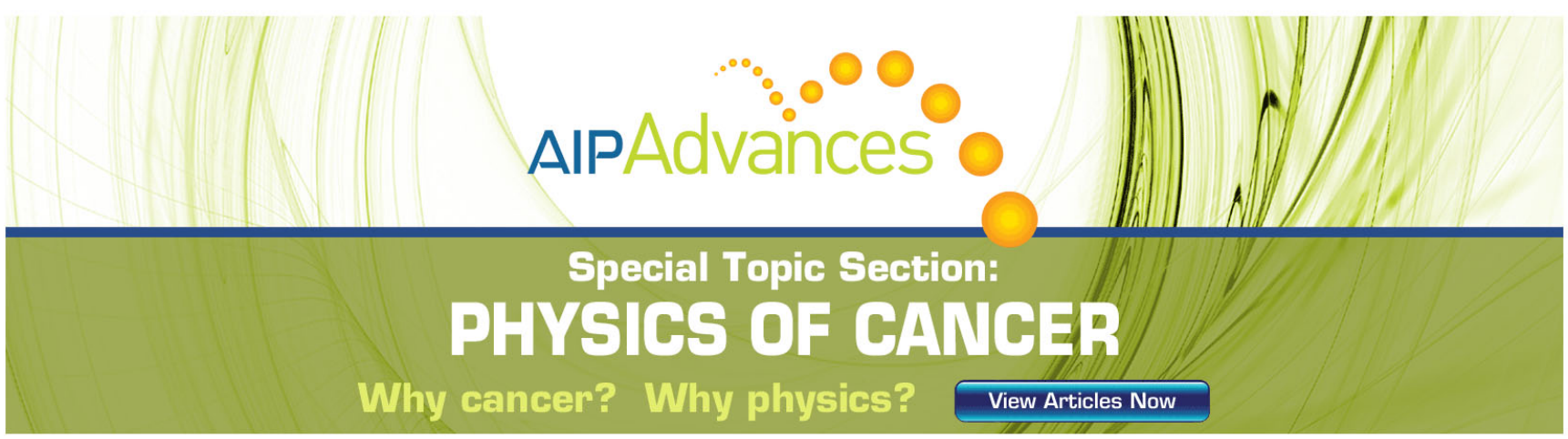




\title{
Relativistic four- and two-component calculations of parity violation effects in chiral tungsten molecules of the form NWXYZ (X, Y, Z=H, F, Cl, Br, or I)
}

\author{
Detlev Figgen, ${ }^{1}$ Trond Saue ${ }^{2}$ and Peter Schwerdtfeger ${ }^{1, a)}$ \\ ${ }^{1}$ Centre for Theoretical Chemistry and Physics, New Zealand Institute for Advanced Study, Massey \\ University Albany, Private Bag 102904, North Shore City, Auckland 0745, New Zealand \\ ${ }^{2}$ Institut de Chimie, CNRS and Université de Strasbourg, Laboratoire de Chimie Quantique, 4 rue Blaise \\ Pascal, F-67070 Strasbourg, France
}

(Received 2 April 2010; accepted 10 May 2010; published online 18 June 2010)

\begin{abstract}
Parity violation $(\mathrm{PV})$ effects to the electronic ground state structure for a series of chiral tungsten molecules of the type NWXYZ (X, Y, Z=H, F, Cl, Br, or I) are compared using four- (Dirac) and two- (X2C) component relativistic Hartree-Fock and density functional theories. The results show the computationally more affordable two-component $\mathrm{X} 2 \mathrm{C}$ approach yields accurate results for all molecules investigated. The PV energy differences between the two enantiomers range from as little as $0.4 \mathrm{~Hz}$ for $\mathrm{NWClBrI}$ to $140 \mathrm{~Hz}$ for NWHCII using a generalized gradient approximation including exact exchange (B3LYP). The $\mathrm{W}-\mathrm{N}$ stretching mode in these molecules lies in the experimentally favorable $\mathrm{CO}_{2}$ laser frequency range, and we therefore investigated $\mathrm{PV}$ effects in vibrational transitions using a single normal mode analysis. Here the PV frequency shift between the two enantiomers ranges from $1.6 \mathrm{mHz}$ for NWFBrI to $710 \mathrm{mHz}$ for NWHClI. Thus these types of molecules could be useful for the future detection of PV effects in chiral molecules. (C) 2010 American Institute of Physics. [doi:10.1063/1.3439692]
\end{abstract}

\section{INTRODUCTION}

It was long believed that left- and right-handed molecules are energetically equivalent in an achiral environment, and perhaps the emergence of biomolecular homochirality on earth with clear preference for one specific enantiomer (Lamino acids and D-sugars) happened just by chance at an early stage of the chemical evolution process. ${ }^{1,2}$ While the origin of biomolecular homochirality is still intensively debated in literature, the pure existence of chiral molecules has been the subject of debate as well, as the ground state of a chiral molecular system with a double-minimum potential connecting the two enantiomers along the inversion path is of positive parity (and not the symmetry-broken chiral states), that is a symmetric linear combination between leftand right-handed states. ${ }^{3,4}$ This controversy was perhaps resolved very recently by Trost and Hornberger ${ }^{5}$ who demonstrated that collisional decoherence stabilizes and therefore superselects the configuration states of chiral molecules.

The situation changes if parity symmetry is violated and cannot be seen anymore as a weak perturbation compared to the tunneling splitting. Here left- and right-handed wave functions are eigenstates of the full Hamiltonian becoming close to coherent superpositions of positive and negative parity states. The weak force mediated by the Z-boson exchange between electrons and nucleons leads to such parity violation (PV) effects in chiral molecules, lifting the degeneracy between enantiomers by $10^{-13} \mathrm{eV}$ or less. ${ }^{6-10}$ However, despite many attempts to measure PV energy shifts in chiral molecules, it has never been unambiguously identified ${ }^{11-13}$ de-

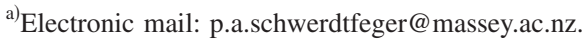

spite a few more optimistic (but irreproducible) claims in the past. Over the past 30 years attempts to measure such tiny effects improved considerably; from a $300 \mathrm{kHz}$ resolution for the first experiment by Arimondo ${ }^{14}$ in 1977 investigating the vibrational spectrum of $d$ - and $l$-camphor using the $9.22 \mu \mathrm{m}$ $\mathrm{R}(28) \mathrm{CO}_{2}$ laser line, to about a current upper limit of $4 \mathrm{~Hz}$ for $\mathrm{CHF}^{37} \mathrm{Cl}^{81} \mathrm{Br}$ by Chardonnet and co-workers ${ }^{11}$ using a single $\mathrm{CO}_{2}$ laser that feeds into an electro-optic modulator generating tunable frequency stabilized sidebands. In the latter setup, the laser goes through two $3 \mathrm{~m}$ long Fabry-Pèrot cavities containing the separated enantiomeric compounds in high optical purity. ${ }^{11}$ A new experimental setup by this group aims at detecting PV shifts in vibrational transitions by supersonic molecular beam spectroscopy using a two-photon Ramsey fringes experiment with a predicted sensitivity of $0.01 \mathrm{~Hz} .{ }^{15,16}$ Another very promising method is to trap molecules at ultracold temperatures in the milliKelvin range or below to perform ultrahigh-resolution spectroscopic measurements. ${ }^{17}$

Whereas experimental techniques are constantly improving and slowly moving into the millihertz resolution range or even below, ${ }^{18,19}$ the synthesis and subsequent enantiomeric purification of chiral compounds suitable for PV experiments is less than straightforward and proves to be a rather challenging task. ${ }^{13,20-25} \mathrm{PV}$ effects are strongly dependent on the chiral system involved and scale approximately like $Z^{5}(Z$ denotes the nuclear charge) for electronic and vibrational transitions. ${ }^{26,27}$ More recently an approximate $Z^{4}$ scaling has been determined for nuclear spin-dependent effects such as NMR chemical shifts. ${ }^{28}$ Thus, the search of large PV effects concentrates on chiral molecules including heavy elements 


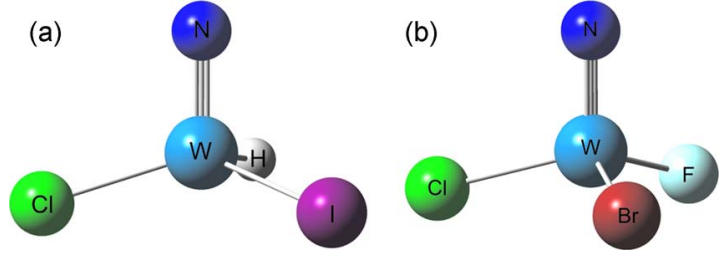

FIG. 1. Minimum geometries of $R$-NWHCII (left) and $S$-NWFClBr (right).

close to the chiral center ${ }^{29-31}$ and a number of chiral compounds containing heavy elements with vibrational transitions in the $\mathrm{CO}_{2}$ laser range have been investigated by quantum theoretical methods in the past. ${ }^{30,32-36}$ More recently Crassous and co-workers investigated a series of new chiral oxorhenium (V) complexes designed for high-resolution laser spectroscopy. However, small and compact molecules are better suited for PV experiments as they provide favorable thermodynamic partition functions. We therefore investigated the chiral molecule NWHCII as a possible candidate to detect such tiny $\mathrm{PV}$ effects, ${ }^{37}$ as the $\mathrm{W}-\mathrm{N}$ stretching frequency lies conveniently in the $\mathrm{CO}_{2}$ laser range. ${ }^{38,39}$ Both B3LYP and local density approximation (LDA) calculations of the corresponding $R$-enantiomer result in rather large $\mathrm{PV}$ total energy shifts of -69 and $-120 \mathrm{~Hz}$, respectively, and in a PV vibrational energy splitting between the enantiomers of $0.71 \mathrm{~Hz}$ (B3LYP) and $0.90 \mathrm{~Hz}$ (LDA). These effects exceed the PV shift calculated for the $\mathrm{Se}-\mathrm{O}$ stretching mode of SeOCII (Refs. 35 and 36) by a factor of 6-8, and the ones for the $\mathrm{C}-\mathrm{F}$ stretching mode of the most promising methane derivative, CHFBrI, ${ }^{40}$ by about two orders of magnitude.

In this paper we compare PV effects obtained from relativistic density functional calculations for a whole range of chiral $\mathrm{N} \equiv \mathrm{WXYZ}$ molecules, as shown in Fig. 1, with $\mathrm{X}, \mathrm{Y}$, and $\mathrm{Z}$ representing hydrogen or the halogens $\mathrm{F}, \mathrm{Cl}, \mathrm{Br}$, and $\mathrm{I}$. These chiral compounds have not yet been synthesized, but even if they are not accessible in solid form, they may still be obtained in the gas phase. Subsequent mass selection and trapping at ultracold temperatures could open the way for high-resolution spectroscopic studies.

\section{COMPUTATIONAL DETAILS}

The minimum structures, normal modes, and harmonic frequencies of all $\mathrm{N} \equiv \mathrm{WXYZ}, \mathrm{N} \equiv \mathrm{WHXY}, \quad$ and
$\mathrm{HN}=\mathrm{WXY}$ molecules $(\mathrm{X}, \mathrm{Y}, \mathrm{Z}=\mathrm{F}, \mathrm{Cl}, \mathrm{Br}$, and I) were obtained from geometry optimizations ${ }^{41}$ within density functional theory (DFT) applying Becke's three parameter hybrid functional (B3LYP). ${ }^{42,43}$ For the lighter elements $(\mathrm{H}, \mathrm{N}, \mathrm{F}$, and $\mathrm{Cl}$ ) all-electron augmented correlation consistent polarized valence triple zeta (AVTZ) basis sets were used, ${ }^{4-46}$ whereas for the heavier elements ( $\mathrm{Br}$, I, and W) AVTZ basis sets in connection with small-core energy-consistent scalar relativistic pseudopotentials (SRPPs) from the Stuttgart group were employed. ${ }^{47,48}$ The accuracy of the pseudopotential approximation for valence properties, if a small core is chosen, has been well documented. ${ }^{49-51}$ In order to verify that the $\mathrm{W}-\mathrm{N}$ stretching frequency fits into the available $\mathrm{CO}_{2}$ laser range, we carried out anharmonic frequency analyses within a normal mode approach within the SRPP approximation. Here we included all coupling terms in the cubic and quartic normal mode force fields according to the method outlined by Barone and co-workers. ${ }^{52,53}$ The perturbative approach, as described in detail by Schaefer and co-workers ${ }^{54}$ and as implemented in GAUSSIAN03, ${ }^{41}$ was used for calculating the fundamental transition frequencies. ${ }^{55-57}$ At each point in the nine-dimensional space the Hessian was derived analytically, while the cubic and quartic force constants were derived numerically. The calculated fundamental vibrational transitions should provide useful information for the detection and characterization of these yet unknown molecules.

The all-electron PV calculations in the four-component (Dirac) picture become quite demanding in computer time, and we therefore used a two-component relativistic Hamiltonian (X2C) instead as described in Refs. 58 and 59. In these two-component calculations, the contribution of the two-electron spin same-orbit coupling is introduced in a mean field fashion, ${ }^{60}$ using the AMFI code,${ }^{61}$ as implemented in the DIRAC program package. ${ }^{62}$ These calculations were carried out at the Hartree-Fock (HF), LDA, and B3LYP levels of theory. At the optimized minimum geometry we validate the applicability of the $\mathrm{X} 2 \mathrm{C}$ method against the more accurate four-component approach for each molecule. In all these calculations, Dunning's AVTZ basis sets were employed in an uncontracted form for the light elements $(\mathrm{H}, \mathrm{N}$, and $\mathrm{F}$ ); for the heavier halogen atoms $(\mathrm{Cl}, \mathrm{Br}$, and $\mathrm{I})$ dual family type basis sets were used which have been detailed in Ref. 36. In a similar fashion, i.e., by augmenting Fægri's

TABLE I. Optimized SRPP/B3LYP structural parameters for the $\mathrm{N} \equiv \mathrm{WHXY}$ molecules in their singlet ground state. Distances $R$ in $\AA$ and angles $\angle$ in degrees. $X$ refers to the lighter halogen ligand in each molecule.

\begin{tabular}{lcccccc}
\hline \hline & NWHFCl & NWHFBr & NWHFI & NWHClBr & NWHCII & NWHBrI \\
\hline$R_{\mathrm{WN}}$ & 1.657 & 1.657 & 1.656 & 1.656 & 1.656 & 1.656 \\
$R_{\mathrm{WH}}$ & 1.710 & 1.710 & 1.710 & 1.707 & 1.707 & 1.706 \\
$R_{\mathrm{WX}}$ & 1.856 & 1.857 & 1.858 & 2.267 & 2.268 & 2.413 \\
$R_{\mathrm{WY}}$ & 2.267 & 2.413 & 2.622 & 2.412 & 2.619 & 2.620 \\
$\angle_{\mathrm{NWH}}$ & 97.4 & 97.5 & 97.7 & 97.3 & 97.4 & 97.4 \\
$\angle_{\mathrm{NWX}}$ & 106.9 & 107.1 & 107.5 & 107.6 & 107.9 & 107.8 \\
$\angle_{\mathrm{NWY}}$ & 107.1 & 107.1 & 106.7 & 107.4 & 106.9 & 107.0 \\
$\angle_{\mathrm{HWX}}$ & 110.8 & 111.1 & 111.5 & 109.6 & 110.1 & 109.5 \\
$\angle_{\mathrm{HWY}}$ & 109.2 & 108.9 & 108.7 & 108.8 & 108.4 & 108.6 \\
$\angle_{\mathrm{XWY}}$ & 122.3 & 122.1 & 121.9 & 123.0 & 123.1 & 123.4 \\
\hline \hline
\end{tabular}


TABLE II. Optimized SRPP/B3LYP structural parameters for the $\mathrm{N} \equiv \mathrm{WXYZ}$ molecules in their singlet ground state. Distances $R$ in $\AA$ and angles $\angle$ in degrees. $X$ refers to the lightest halogen ligand in each molecule and $Z$ to the heaviest halogen.

\begin{tabular}{lcccc}
\hline \hline & NWFClBr & NWFCII & NWFBrI & NWClBrI \\
\hline$R_{\mathrm{WN}}$ & 1.656 & 1.656 & 1.656 & 1.656 \\
$R_{\mathrm{WX}}$ & 1.855 & 1.856 & 1.856 & 2.268 \\
$R_{\mathrm{WY}}$ & 2.268 & 2.274 & 2.417 & 2.415 \\
$R_{\mathrm{WZ}}$ & 2.416 & 2.625 & 2.626 & 2.624 \\
$\angle_{\mathrm{NWX}}$ & 105.5 & 105.8 & 105.9 & 105.9 \\
$\angle_{\mathrm{NWY}}$ & 105.6 & 105.8 & 105.6 & 105.6 \\
$\angle_{\mathrm{NWZ}}$ & 105.3 & 104.8 & 104.8 & 104.7 \\
$\angle_{\mathrm{XWY}}$ & 113.4 & 114.0 & 113.8 & 113.7 \\
$\angle_{\mathrm{XWZ}}$ & 113.1 & 112.6 & 112.8 & 113.0 \\
$\angle_{\mathrm{YWZ}}$ & 112.9 & 112.8 & 112.9 & 112.9 \\
\hline \hline
\end{tabular}

dual family basis set, ${ }^{63}$ we constructed a $24 s 22 p 16 d 11 f 4 g$ basis set for $\mathrm{W}$; the exponents of the additional augmentation functions were 0.0142 for $s, 0.105,0.04$, and 0.015 for $p$, 0.0142 for $d$, and 0.105 for $f$.

The PV energy shifts, $E_{\mathrm{PV}}$, were obtained from the expectation value,

$$
E_{\mathrm{PV}}=\sum_{n} \epsilon_{\mathrm{PV}}(n)=\sum_{n} \sum_{i}\left\langle\Phi_{i}\left|H_{\mathrm{PV}}(i, n)\right| \Phi_{i}\right\rangle,
$$

with the $\Phi_{i}$ being the HF or DFT spinors and $H_{\mathrm{PV}}$ the nuclear spin-independent $P$-odd operator,

$$
H_{\mathrm{PV}}(i, n)=\frac{G_{F}}{2 \sqrt{2}} Q_{W, n} \gamma_{i}^{5} \rho_{n}\left(r_{i n}\right) .
$$

Here,

$$
G_{F}=2.22255 \times 10^{-14} \text { a.u. }
$$

$\left.\times 10^{-62} \mathrm{~J} \mathrm{~m}^{3}\right)$ is the Fermi coupling constant and $\gamma_{i}^{5}$ is the pseudochirality Dirac four matrix,

$$
\gamma^{5}=\left(\begin{array}{ll}
0_{2} & 1_{2} \\
1_{2} & 0_{2}
\end{array}\right)
$$

with $1_{2}$ and $0_{2}$ being the $2 \times 2$ identity and zero matrix, respectively. The summation in Eq. (1) runs over all electrons $i$ and nucleons $n$, and the nuclear charge distributions $\rho_{n}\left(r_{i n}\right)$ (Ref. 64) were chosen to be of Gaussian-type as described in Refs. 27 and 65. $\epsilon_{\mathrm{PV}}(n)$ are the individual PV energy shifts for each atom $n$. The weak charge of nucleus $n, Q_{W, n}$, is given by $Q_{W, n}=-N_{n}+Z_{n}\left(1-4 \sin ^{2} \theta_{W}\right)$, where $N_{n}$ and $Z_{n}$ are the numbers of neutrons and protons of nucleus $n$, respectively. For the Weinberg mixing angle, $\theta_{W}$, a value of $\sin ^{2} \theta_{W}=0.2319$ was chosen. The total number of nucleons, i.e., $N_{n}+Z_{n}$, for $\mathrm{H}, \mathrm{N}, \mathrm{F}, \mathrm{Cl}, \mathrm{Br}$, I, and $\mathrm{W}$ were chosen to be $1,14,19,35,79,127$, and 184 , respectively.

For the single mode analysis of the PV shift in the vibrational frequency, $E_{\mathrm{PV}}(q)$ was calculated pointwise along the normal coordinate $q$ of the $\mathrm{W}-\mathrm{N}$ stretching mode and afterward fitted to a polynomial. The outermost points of the calculated potential curves were equivalent to a displacement along the normalized gradient vector of $\pm 0.5 \AA$. This normal mode nearly exclusively describes the change in the $\mathrm{N}-\mathrm{W}$ distance, and a displacement of $0.5 \AA$ is equivalent to an elongation of the $\mathrm{N}-\mathrm{W}$ bond by $0.536 \AA$. As the single-

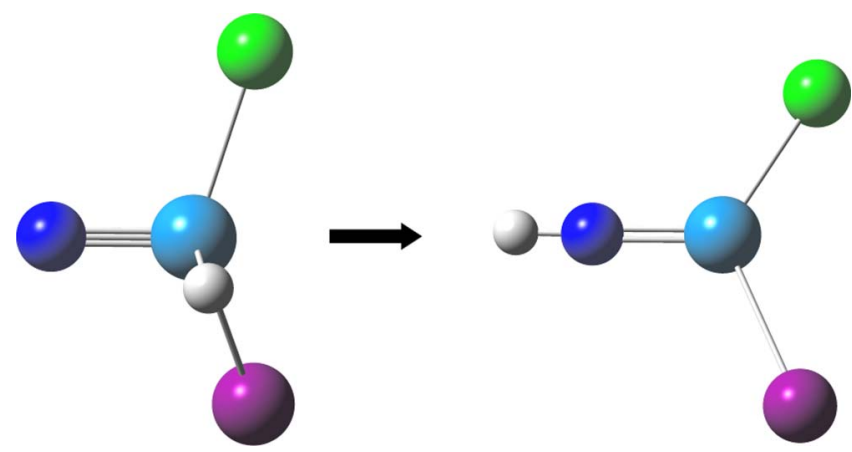

FIG. 2. The rearrangement from $\mathrm{N} \equiv \mathrm{WHXY}$ to the $\mathrm{HN}=\mathrm{WXY}$ isomer by a hydrogen shift reaction.

reference $\mathrm{HF}$ method shows instabilities in describing the elongation of the $\mathrm{N} \equiv \mathrm{W}$ triple bond, a fit to a polynomial over the whole range proved impractical (see Fig. 2 in Ref. 37). Consequently, the vibrational PV shifts were obtained at the DFT level only. The PV-induced energy shift $\nu_{\mathrm{PV}}^{n}$ on the state with vibrational quantum number $n$ was then obtained as the expectation value over the single mode vibrational wave function $\Psi_{n}$ obtained from a numerical NumerovCooley procedure ${ }^{66,67}$ along the normal coordinate $q$,

$$
\nu_{\mathrm{PV}}^{n}=\left\langle\Psi_{n}(q)\left|E_{\mathrm{PV}}(q)\right| \Psi_{n}(q)\right\rangle .
$$

The PV contribution to the vibrational transition $n \rightarrow m$ then is $\Delta \nu_{\mathrm{PV}}^{n \rightarrow m}=\nu_{\mathrm{PV}}^{m}-\nu_{\mathrm{PV}}^{n}$. This single mode analysis includes all anharmonicity effects within this mode and is a very good approximation for vibrational states, which are well separated in the considered frequency range.

Concerning the enantiomers chosen we use the $R$-configuration for the hydrogen containing $\mathrm{N} \equiv \mathrm{WHXY}$ molecules and the $S$-configuration for the hydrogen free $\mathrm{N} \equiv \mathrm{WXYZ}$ molecules $(\mathrm{X}, \mathrm{Y}, \mathrm{Z}=\mathrm{F}, \mathrm{Cl}, \mathrm{Br}, \mathrm{I})$. The substitution of the hydrogen by a halogen atom leads to a change in priority of the ligands according to the Cahn-Ingold-Prelog rules; ${ }^{6}$ in the $\mathrm{N} \equiv \mathrm{WXYZ}$ molecules $\mathrm{N}$ now is the atom of lowest priority instead of $\mathrm{H}$ in the $\mathrm{N} \equiv$ WHXY molecules. Therefore, as we retain the handedness when looking down the $\mathrm{N} \equiv \mathrm{W}$ axis (see Fig. 1), the Cahn-Ingold-Prelog assignment of configuration changes from $R$ to $S$. Thus, a change in sign in $E_{\mathrm{PV}}$ between different molecules is then caused by a change in ligand and not by the Cahn-Ingold-Prelog rules.

TABLE III. Energy differences (in $\mathrm{kcal} / \mathrm{mol}$ ) between the $\mathrm{N} \equiv \mathrm{WHXY}$ and the $\mathrm{HN}=\mathrm{WXY}$ isomers $(\mathrm{X}, \mathrm{Y}=\mathrm{F}, \mathrm{Cl}, \mathrm{Br}, \mathrm{I})$ at the SRPP/B3LYP level of theory. For the $\mathrm{N} \equiv \mathrm{WHXY}$ isomers only the singlet state needs to be considered.

\begin{tabular}{lcccc}
\hline \hline & N $\equiv$ WHXY & & \multicolumn{2}{c}{ HN=WXY } \\
\cline { 2 - 3 } \cline { 5 - 5 } X, Y & Singlet & & Singlet & Triplet \\
\hline $\mathrm{F}, \mathrm{Cl}$ & 0.00 & & 2.89 & 3.54 \\
$\mathrm{~F}, \mathrm{Br}$ & 0.00 & & 3.75 & 2.98 \\
$\mathrm{~F}, \mathrm{I}$ & 0.00 & & 5.14 & 2.09 \\
$\mathrm{Cl}, \mathrm{Br}$ & 0.00 & & 4.69 & 0.62 \\
$\mathrm{Cl}, \mathrm{I}$ & 0.00 & & 5.76 & 0.06 \\
$\mathrm{Br}, \mathrm{I}$ & 0.20 & & 6.45 & 0.00 \\
\hline
\end{tabular}


TABLE IV. Calculated SRPP/B3LYP harmonic $(\omega)$ and anharmonic $(\nu)$ vibrational frequencies, and rotational constants $\left(A_{e}, B_{e}, C_{e}\right)$ of the $\mathrm{N} \equiv$ WHXY molecules in their singlet ground state $\left(\mathrm{in}^{-1}\right)$. Infrared intensities (in $\mathrm{km} / \mathrm{mol}$ ) are given in parentheses.

\begin{tabular}{lcccccc}
\hline \hline Mode & NWHFCl & NWHFBr & NWHFI & NWHClBr & NWHClI & NWHBrI \\
\hline$\omega_{1}$ & $2024.5(75)$ & $2021.8(77)$ & $2018.2(81)$ & $2020.3(68)$ & $2016.8(71)$ & $2014.5(69)$ \\
$\nu_{1}$ & 1963.8 & 1960.1 & 1955.9 & 1958.7 & 1953.6 & 1952.0 \\
$\omega_{2}$ & $1144.4(52)$ & $1143.5(55)$ & $1142.5(58)$ & $1141.1(54)$ & $1140.3(55)$ & $1139.6(55)$ \\
$\nu_{2}$ & 1136.2 & 1135.4 & 1134.5 & 1133.0 & 1132.2 & 1131.6 \\
$\omega_{3}$ & $706.9(95)$ & $705.0(89)$ & $704.2(83)$ & $692.1(7)$ & $692.5(7)$ & $692.4(6)$ \\
$\nu_{3}$ & 700.4 & 699.9 & 698.9 & 689.1 & 688.8 & 688.2 \\
$\omega_{4}$ & $680.1(38)$ & $678.2(41)$ & $676.1(46)$ & $588.6(9)$ & $577.7(5)$ & $565.3(0.3)$ \\
$\nu_{4}$ & 676.0 & 673.7 & 670.8 & 586.0 & 571.6 & 562.6 \\
$\omega_{5}$ & $597.4(8)$ & $588.0(4)$ & $578.9(4)$ & $399.3(52)$ & $396.3(55)$ & $289.8(37)$ \\
$\nu_{5}$ & 592.5 & 582.0 & 570.9 & 396.8 & 393.5 & 288.5 \\
$\omega_{6}$ & $406.7(41)$ & $320.4(14)$ & $307.2(7)$ & $290.5(16)$ & $268.0(6)$ & $236.0(3)$ \\
$\nu_{6}$ & 404.7 & 319.0 & 305.2 & 289.0 & 266.3 & 235.1 \\
$\omega_{7}$ & $304.5(1)$ & $254.9(10)$ & $202.6(11)$ & $243.0(4)$ & $197.9(8)$ & $195.5(7)$ \\
$\nu_{7}$ & 302.5 & 253.9 & 201.5 & 242.1 & 196.8 & 194.5 \\
$\omega_{8}$ & $201.2(9)$ & $183.4(8)$ & $170.5(7)$ & $157.3(7)$ & $147.9(7)$ & $136.6(7)$ \\
$\nu_{8}$ & 201.0 & 184.0 & 170.7 & 158.1 & 148.2 & 135.7 \\
$\omega_{9}$ & $126.4(6)$ & $113.6(4)$ & $106.5(3)$ & $78.2(1)$ & $70.8(1)$ & $53.9(0.5)$ \\
$\nu_{9}$ & 126.7 & 113.9 & 106.3 & 76.8 & 68.9 & 52.6 \\
$A_{e}$ & 0.21958 & 0.21324 & 0.21035 & 0.13352 & 0.12724 & 0.08672 \\
$B_{e}$ & 0.07954 & 0.04104 & 0.02630 & 0.03373 & 0.02250 & 0.01646 \\
$C_{e}$ & 0.06540 & 0.03684 & 0.02450 & 0.02858 & 0.01996 & 0.01429 \\
\hline \hline
\end{tabular}

\section{RESULTS AND DISCUSSION}

The optimized B3LYP distances and angles for all $\mathrm{N} \equiv \mathrm{WXYZ}$ and $\mathrm{N} \equiv \mathrm{WHXY}$ molecules in their singlet ground state are collected in Tables I and II. Note that the stiff $\mathrm{N} \equiv \mathrm{W}$ triple bond shows little variation in the bond length. Moreover, the other single bonds do not vary much either between the different molecules and the same can be observed for the N-W-X bond angles. The latter are close to the ideal tetrahedral angle, whereas the $\mathrm{N}-\mathrm{W}-\mathrm{H}$ bond angle is smaller and between $97.4^{\circ}$ and $97.7^{\circ}$. For the thermodynamic stability of these single molecules we need to consider the hydrogen shift leading to molecules of the general formula $\mathrm{HN}=\mathrm{WXY}$, as shown in Fig. 2. Moreover, both singlet and triplet states need to be considered for these isomers as the hydrogen shift formally reduces $\mathrm{W}(\mathrm{VI})$ to $\mathrm{W}(\mathrm{IV})$. All optimized $\mathrm{HN}=\mathrm{WXY}$ structures are found to be planar or very close to planarity with $\mathrm{H}-\mathrm{N}-\mathrm{W}$ bond angles close to $180^{\circ}$. These isomers are practically achiral and therefore we did not investigate PV effects in these molecules. We note that the corresponding rearrangement by a halogen shift to $\mathrm{XN}=\mathrm{WYZ}$ is energetically not favored and that the $\mathrm{N} \equiv \mathrm{WXYZ}$ molecules are thermodynamically stable toward decomposition. ${ }^{37}$ For the $\mathrm{N} \equiv \mathrm{WHXY}$ molecules, however, the two different isomers and spin states are rather close in energy (see Table III). In fact, in the case of NWH$\mathrm{BrI}$, triplet $\mathrm{HN}=\mathrm{WBrI}$ represents the ground state (at the B3LYP level of theory). However, the energy difference between the two isomers is only $0.2 \mathrm{kcal} / \mathrm{mol}$ (not corrected for zero-point vibrational effects), and more accurate coupled cluster calculations are needed to correctly determine the global minimum. These low-lying $\mathrm{HN}=\mathrm{WXY}$ states might complicate the handling of these molecules in the gas phase but they should not influence the detection of PV by using tunable $\mathrm{CO}_{2}$ lasers. The $\mathrm{N}-\mathrm{W}$ bond in a $\mathrm{HN}=\mathrm{WXY}$ molecule is formally a double bond and therefore, weaker than the triple bond in the $\mathrm{N} \equiv \mathrm{WHXY}$ molecule; accordingly, the $\mathrm{N}-\mathrm{W}$ bonds in the HNW $=\mathrm{XY}$ isomers are about 0.065 $0.070 \AA$ longer than in the corresponding $\mathrm{N} \equiv$ WHXY mol-

TABLE V. Calculated SRPP/B3LYP harmonic $(\omega)$ and anharmonic $(\nu)$ vibrational frequencies, and rotational constants $\left(A_{e}, B_{e}, C_{e}\right)$ of the $\mathrm{N}$ $\equiv \mathrm{WXYZ}$ molecules in their singlet ground state (in $\mathrm{cm}^{-1}$ ). Infrared intensities (in $\mathrm{km} / \mathrm{mol}$ ) are given in parentheses.

\begin{tabular}{lcccc}
\hline \hline Mode & NWFClBr & NWFCII & NWFBrI & NWClBrI \\
\hline$\omega_{1}$ & $1141.6(53)$ & $1140.1(54)$ & $1139.1(54)$ & $1136.6(50)$ \\
$\nu_{1}$ & 1134.0 & 1132.4 & 1131.8 & 1130.4 \\
$\omega_{2}$ & $683.6(106)$ & $681.1(108)$ & $679.2(107)$ & $403.7(59)$ \\
$\nu_{2}$ & 677.5 & 674.6 & 672.7 & 401.2 \\
$\omega_{3}$ & $410.8(58)$ & $408.7(59)$ & $314.1(12)$ & $289.1(33)$ \\
$\nu_{3}$ & 408.1 & 406.1 & 312.4 & 288.5 \\
$\omega_{4}$ & $316.4(16)$ & $308.3(6)$ & $285.8(37)$ & $263.2(9)$ \\
$\nu_{4}$ & 314.7 & 306.1 & 284.5 & 265.8 \\
$\omega_{5}$ & $286.4(14)$ & $266.2(11)$ & $237.9(1)$ & $236.5(1)$ \\
$\nu_{5}$ & 284.9 & 264.7 & 236.8 & 236.6 \\
$\omega_{6}$ & $245.0(1)$ & $202.3(5)$ & $199.6(4)$ & $197.9(4)$ \\
$\nu_{6}$ & 243.9 & 201.3 & 199.0 & 198.1 \\
$\omega_{7}$ & $148.5(2)$ & $144.5(2)$ & $133.0(0.4)$ & $101.7(0.2)$ \\
$\nu_{7}$ & 148.3 & 142.8 & 131.0 & 101.5 \\
$\omega_{8}$ & $137.8(1)$ & $130.5(0.6)$ & $125.2(1)$ & $87.8(0.01)$ \\
$\nu_{8}$ & 137.9 & 129.2 & 123.7 & 87.8 \\
$\omega_{9}$ & $91.0(0.4)$ & $83.6(0.2)$ & $63.9(0.04)$ & $63.5(0.01)$ \\
$\nu_{9}$ & 90.3 & 82.2 & 63.9 & 65.1 \\
$A_{e}$ & 0.07531 & 0.07374 & 0.05001 & 0.035226 \\
$B_{e}$ & 0.03278 & 0.02182 & 0.01725 & 0.016645 \\
$C_{e}$ & 0.02716 & 0.01909 & 0.01411 & 0.012780 \\
\hline \hline & & & &
\end{tabular}


TABLE VI. PV energy shifts $E_{\mathrm{PV}}$ for each molecule at equilibrium geometry at the four-component Dirac (D) and two-component $(\mathrm{X} 2 \mathrm{C})$ level of theory using HF, the LDA, and the B3LYP hybrid functional. The last column shows the results for the individual PV contribution at the $\mathrm{W}$ atom, $\epsilon_{\mathrm{PV}}(\mathrm{W})$, calculated at $\mathrm{X} 2 \mathrm{C}-\mathrm{B} 3 \mathrm{LYP}$ level. All values are in $\mathrm{Hz}$.

\begin{tabular}{lrrrrrrr}
\hline \hline Molecule & D-HF & X2C-HF & D-LDA & X2C-LDA & D-B3LYP & X2C-B3LYP & $\epsilon_{\mathrm{PV}}(\mathrm{W})$ \\
\hline$R$-NWHFCl & 2.55 & 2.40 & 2.60 & 2.37 & 3.90 & 3.69 & 3.76 \\
$R$-NWHFBr & 14.46 & 14.17 & -24.55 & -24.49 & -7.56 & -7.76 & -6.72 \\
$R$-NWHFI & 33.73 & 33.60 & -64.54 & -64.00 & -24.90 & -24.87 & -19.70 \\
$R$-NWHClBr & 3.84 & 3.85 & -47.27 & -46.63 & -27.08 & -26.78 & -26.29 \\
$R$-NWHClI & 12.85 & 13.05 & -120.93 & -119.58 & -69.20 & -68.54 & -66.43 \\
$R$-NWHBrI & 10.69 & 10.90 & -75.30 & -74.50 & -42.36 & -41.96 & -42.24 \\
$S$-NWFClBr & -7.97 & -7.83 & -14.52 & -14.20 & -11.98 & -11.73 & -12.09 \\
$S$-NWFCII & -17.81 & -17.57 & -38.86 & -38.33 & -30.67 & -30.29 & -32.50 \\
$S$-NWFBrI & -8.27 & -8.12 & -25.36 & -25.09 & -18.79 & -18.61 & -21.59 \\
$S$-NWClBrI & 1.68 & 1.68 & -1.21 & -1.18 & -0.21 & -0.21 & -1.34 \\
\hline \hline
\end{tabular}

ecules. As a consequence, the vibrational frequencies of the $\mathrm{W}-\mathrm{N}$ stretching mode for the $\mathrm{HN}=\mathrm{WXY}$ isomers will be much smaller than for the corresponding $\mathrm{N} \equiv \mathrm{WHXY}$ molecules and can easily be differentiated.

To assist further identification of these compounds, the anharmonic frequencies of all $\mathrm{N} \equiv \mathrm{WXYZ}$ molecules have been calculated and are listed in Tables IV and V in comparison with the harmonic values. Tables IV and V also list the calculated equilibrium rotational constants. For all molecules, the frequency of the $\mathrm{W}-\mathrm{N}$ stretching mode is nearly independent of the other ligands and lies between 1130 and $1136 \mathrm{~cm}^{-1}$ at the B3LYP level of theory. However, the calculated frequencies overestimate the experimental transition frequencies; to estimate the extent of this overestimation, the vibrational frequencies of $\mathrm{N} \equiv \mathrm{WH}_{3}$ and $\mathrm{N} \equiv \mathrm{WF}_{3}$ were calculated as well, which are 1148 and $1143 \mathrm{~cm}^{-1}$ for $\mathrm{N} \equiv \mathrm{WH}_{3}$ and $\mathrm{N} \equiv \mathrm{WF}_{3}$, respectively. This compares to the experimental frequencies of $1092 \mathrm{~cm}^{-1}$ for $\mathrm{N} \equiv \mathrm{WH}_{3}$ and $1091 \mathrm{~cm}^{-1}$ for $\mathrm{N} \equiv \mathrm{WF}_{3}{ }^{38,39}$ We therefore conclude that B3LYP overestimates all calculated anharmonic frequencies for the $\mathrm{W}-\mathrm{N}$ stretching mode by about $50 \mathrm{~cm}^{-1}$, and the experimental frequencies of the chiral molecules should lie in the vicinity of $1080 \mathrm{~cm}^{-1}$ and thus within the frequency range of the tunable $\mathrm{CO}_{2}$ laser. In addition to the $\mathrm{W}-\mathrm{N}$ mode, the frequencies at $\sim 1960, \sim 675$, and $\sim 400 \mathrm{~cm}^{-1}$ can be assigned to $\mathrm{W}-\mathrm{H}, \mathrm{W}-\mathrm{F}$, and $\mathrm{W}-\mathrm{Cl}$ stretching modes, respectively. The $\mathrm{W}-\mathrm{Br}$ and $\mathrm{W}-\mathrm{I}$ stretching modes at $\sim 290$ and $\sim 200 \mathrm{~cm}^{-1}$, respectively, come at low frequencies. However, they couple substantially with the bending modes and in the case of NWHFBr, for example, it becomes difficult to identify the $\mathrm{W}-\mathrm{Br}$ stretching mode as it is contained in both modes at 319 and $254 \mathrm{~cm}^{-1}$. The measured $\mathrm{W}-\mathrm{H}$ stretching frequencies at 1917 and $1924 \mathrm{~cm}^{-1}$ for $\mathrm{N} \equiv \mathrm{WH}_{3}$ (Ref. 38) are in better agreement with our B3LYP (anharmonic) values of 1910 and $1929 \mathrm{~cm}^{-1}$. Similarly, the measured $\mathrm{W}-\mathrm{F}$ stretching frequencies at 693 and $699 \mathrm{~cm}^{-1}$ for $\mathrm{N} \equiv \mathrm{WF}_{3}$ (Ref. 39) are in good agreement with our calculated values of 683 and $687 \mathrm{~cm}^{-1}$, respectively. $\mathrm{N} \equiv \mathrm{WCl}_{3}$ is known since 1965 (Refs. 69-71) and the structure and bonding were investigated by Schoeller and Sundermann ${ }^{72}$ using DFT. Their calculated $\mathrm{W}-\mathrm{N}$ stretching frequency of $1131 \mathrm{~cm}^{-1}$ (Ref. 72) is in the same range as ours and the experimental value for this mode is $1086 \mathrm{~cm}^{-1} \cdot{ }^{71}$ In order to obtain more accurate vibrational frequencies, coupled cluster calculations are required. In this case the differences between the harmonic and anharmonic frequencies, as shown in Tables IV and V, could be used for the anharmonic corrections to such coupled cluster results.

Table VI shows the differences between the fourcomponent Dirac and the two-component X2C results. They are generally within $3 \%$ accuracy of each other with the exception of the very small $E_{\mathrm{PV}}$ value of $\mathrm{N} \equiv \mathrm{WHFCl}$. Nevertheless, these deviations are much smaller than the differences between the results obtained from the different DFT approximations, B3LYP, and LDA. As the X2C approximation leads to a considerable speed-up in computation time of $\sim 5$ and, in general, also to faster SCF convergence, all subsequent $\mathrm{PV}$ calculations were performed using this approximation.

The results of both DFT methods (LDA and B3LYP) agree fairly well for the $\mathrm{N} \equiv \mathrm{WXYZ}$ molecules $(\mathrm{X}, \mathrm{Y}, \mathrm{Z}$

TABLE VII. Individual and total parity violating contributions, $\epsilon_{\mathrm{PV}}$ and $E_{\mathrm{PV}}$ (in $E_{h}$ ), and dipole moments $\mu$ (in D) at the equilibrium geometry of $R$-NWHClI.

\begin{tabular}{|c|c|c|c|c|c|c|}
\hline & $\mathrm{D}-\mathrm{HF}$ & $\mathrm{X} 2 \mathrm{C}-\mathrm{HF}$ & D-LDA & X2C-LDA & D-B3LYP & X2C-B3LYP \\
\hline$\epsilon_{\mathrm{PV}}(\mathrm{N})$ & $2.554 \times 10^{-20}$ & $2.642 \times 10^{-20}$ & $3.330 \times 10^{-19}$ & $3.256 \times 10^{-19}$ & $1.857 \times 10^{-19}$ & $1.807 \times 10^{-19}$ \\
\hline$\epsilon_{\mathrm{PV}}(\mathrm{W})$ & $2.299 \times 10^{-15}$ & $2.326 \times 10^{-15}$ & $-1.800 \times 10^{-14}$ & $-1.779 \times 10^{-14}$ & $-1.020 \times 10^{-14}$ & $-1.010 \times 10^{-14}$ \\
\hline$\epsilon_{\mathrm{PV}}(\mathrm{H})$ & $-2.492 \times 10^{-23}$ & $-1.660 \times 10^{-23}$ & $-4.468 \times 10^{-22}$ & $-4.345 \times 10^{-22}$ & $-3.381 \times 10^{-22}$ & $-3.268 \times 10^{-22}$ \\
\hline$\epsilon_{\mathrm{PV}}(\mathrm{Cl})$ & $-5.228 \times 10^{-18}$ & $-5.279 \times 10^{-18}$ & $-1.779 \times 10^{-17}$ & $-1.759 \times 10^{-17}$ & $-1.542 \times 10^{-17}$ & $-1.530 \times 10^{-17}$ \\
\hline$E_{\mathrm{PV}}$ (a.u.) & $1.953 \times 10^{-15}$ & $1.983 \times 10^{-15}$ & $-1.838 \times 10^{-14}$ & $-1.817 \times 10^{-14}$ & $-1.052 \times 10^{-14}$ & $-1.042 \times 10^{-14}$ \\
\hline$E_{\mathrm{PV}}(\mathrm{Hz})$ & 12.85 & 13.05 & -120.93 & -119.58 & -69.20 & -68.54 \\
\hline$\mu$ & 2.382 & 2.377 & 2.513 & 2.507 & 2.476 & 2.471 \\
\hline
\end{tabular}



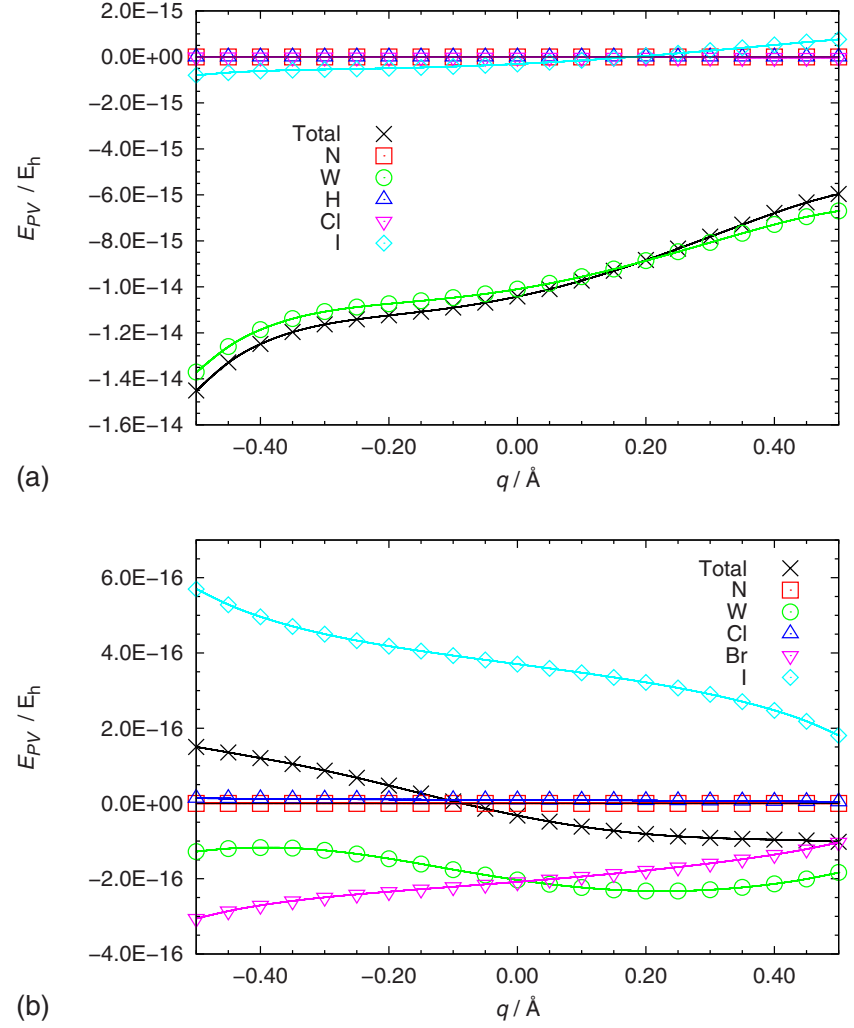

FIG. 3. Total parity violating energy $E_{\mathrm{PV}}$ and individual contributions $\epsilon_{\mathrm{PV}}$ along the normal mode of $R$-NWHCII (upper figure) and $S$-NWClBrI (lower figure) at the B3LYP level of theory.

$=\mathrm{F}, \mathrm{Cl}, \mathrm{Br}, \mathrm{I})$ and are also consistent with the DHF results, but the two DFT results differ by a factor about 2-3 for the $\mathrm{N} \equiv$ WHXY molecules and, even more, for the DHF values we also observe sign changes. Thus it seems that the hydrogen containing molecules are harder to describe correctly than the hydrogen free molecules. The largest $E_{\mathrm{PV}}$ values appear for $\mathrm{N} \equiv$ WHClI, with $E_{\mathrm{PV}}$ nearly completely accounted for by the individual PV contribution at the $\mathrm{W}$ atom, $\epsilon_{\mathrm{PV}}(\mathrm{W})$ (see Table VII). Figure 3 shows that for this molecule the dominance of the individual PV contribution at the $\mathrm{W}$ atom appears at all points along the normal mode; the second to largest individual PV contribution is found at the

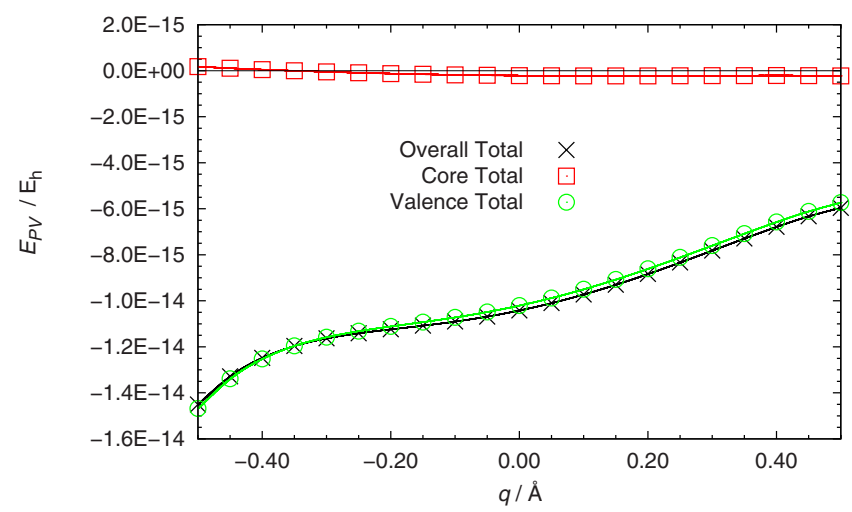

FIG. 4. Total parity violating energy shift $E_{\mathrm{PV}}$ along the normal mode of $R$-NWHClI for the individual core and valence contributions at B3LYP level of theory.

iodine atom. Around the equilibrium geometry, $\epsilon_{\mathrm{PV}}(\mathrm{I})$ has the same sign as $\epsilon_{\mathrm{PV}}(\mathrm{W})$ and therefore slightly enhances the overall PV energy $E_{\mathrm{PV}}$; along the normal coordinate describing the $\mathrm{W}-\mathrm{N}$ stretching mode, $\epsilon_{\mathrm{PV}}(\mathrm{I})$ changes sign and becomes positive for $q \geq 0.20 \AA$, and therefore slightly reduces the overall amount of $E_{\mathrm{PV}}$. This dominance of $\epsilon_{\mathrm{PV}}(\mathrm{W})$ is also found for the other $\mathrm{N} \equiv \mathrm{WHXY}$ molecules and for $\mathrm{N} \equiv \mathrm{WFClBr}, \mathrm{N} \equiv \mathrm{WFClI}$, and $\mathrm{N} \equiv$ WFBrI. However, a completely different situation arises for $\mathrm{N} \equiv \mathrm{WClBrI}$ also shown in Fig. 3: Here three individual PV contributions $\left[\epsilon_{\mathrm{PV}}(\mathrm{W}), \epsilon_{\mathrm{PV}}(\mathrm{Br})\right.$, and $\left.\epsilon_{\mathrm{PV}}(\mathrm{I})\right]$ are of the same order of magnitude and cancel each other to a large extent, leading to a comparatively small value of $E_{\mathrm{PV}}$ at the equilibrium geometry. This shows that one needs to carefully select ligands for a heavy element chiral molecule as different PV energy contributions can lead to cancellation effects. Similar observations were made in chiral carbon compounds. ${ }^{32}$

To demonstrate that the major contribution for the PV energy shift comes from the valence orbitals, we separated the core and valence orbitals for $\mathrm{N} \equiv$ WHClI, with the valence space having $1,5,7,7$, and 6 valence electrons for $\mathrm{H}$, $\mathrm{N}, \mathrm{Cl}$, I and $\mathrm{W}$, giving 13 Kramers pairs for the valence space. Figure 4 clearly shows that the PV is mainly accounted for by the valence orbitals and the total core contributions are almost negligible along the whole $\mathrm{W}-\mathrm{N}$ normal

TABLE VIII. Parity violating contributions $\Delta \nu_{\mathrm{PV}}^{0 \rightarrow m}$ to vibrational transitions for the $\mathrm{W}-\mathrm{N}$ stretching mode (in $\mathrm{mHz}$ ) of the $\mathrm{N} \equiv \mathrm{WHXY}$ and $\mathrm{N} \equiv \mathrm{WXYZ}$ molecules. Calculations were performed at the B3LYP level unless stated otherwise.

\begin{tabular}{lrrrrr}
\hline \hline Molecule & $0 \rightarrow 1$ & $0 \rightarrow 2$ & $0 \rightarrow 3$ & $0 \rightarrow 4$ & $0 \rightarrow 5$ \\
\hline$R$-NWHFCl & 56.3 & 110.3 & 161.8 & 210.6 & 256.2 \\
$R$-NWHFBr & 132.4 & 263.0 & 391.5 & 517.6 & 640.9 \\
$R$-NWHFI & 254.4 & 507.8 & 760.0 & 1010.5 & 1258.7 \\
$R$-NWHClBr & 130.2 & 261.9 & 395.2 & 530.0 & 666.3 \\
$R$-NWHClI & 354.9 & 714.0 & 1077.3 & 1444.9 & 1816.4 \\
$R$-NWHClI, LDA & 450.2 & 908.2 & 1374.2 & 1848.6 & 2331.3 \\
$R$-NWHBrI & 225.4 & 453.6 & 684.5 & 918.3 & 1154.6 \\
$S$-NWFClBr & 2.2 & 4.9 & 8.2 & 12.0 & 16.3 \\
$S$-NWFCII & 11.5 & 24.2 & 38.4 & 53.9 & 70.7 \\
$S$-NWFCII, LDA & 27.9 & 57.2 & 88.2 & 120.7 & 154.9 \\
$S$-NWFBrI & 0.8 & 2.4 & 5.1 & 8.6 & 13.1 \\
$S$-NWClBrI & -5.4 & -10.8 & -16.0 & -21.2 & -26.2 \\
\hline \hline
\end{tabular}


coordinate. This is due to the fact that the core PV contributions in each completed shell cancel out each other as the core space is little polarized by the chiral ligand field. Similar to other core properties, such as the electric field gradient, ${ }^{73}$ which probe the wave function close to the nucleus, the main PV contribution comes from the inner (core) part of the valence orbitals.

Turning now to the PV effects on vibrational transitions for the $\mathrm{W}-\mathrm{N}$ stretching mode, they differ by two orders of magnitudes between the different molecules (see Table VIII), with the $\mathrm{N} \equiv$ WHXY molecules showing much larger effects than the $\mathrm{N} \equiv \mathrm{WXYZ}$ molecules. This bears witness to the fact that the $N \equiv$ WHXY molecules are more asymmetric than the $\mathrm{N} \equiv \mathrm{WXYZ}$ molecules $(\mathrm{X}, \mathrm{Y}, \mathrm{Z}=\mathrm{F}, \mathrm{Cl}, \mathrm{Br}, \mathrm{I})$, i.e., hydrogen differs more from the halides than the halides differ between each other and thus increases the "chirality" for these molecules. We note that for most molecules, the relation $\Delta \epsilon_{\mathrm{PV}}^{0 \rightarrow n} \approx n \Delta \epsilon_{\mathrm{PV}}^{0 \rightarrow 1}$ holds quite well; even more, the vibrational PV effects often follow the formula $\Delta \nu_{\mathrm{PV}}^{0 \rightarrow n}=a_{1} n$ $+a_{2} n^{2}$. For the molecule with the largest effects, $\mathrm{N} \equiv$ WHCII, $a_{1}$ and $a_{2}$ are 353 and $2 \mathrm{mHz}$ at the X2CB3LYP and 446 and $4 \mathrm{mHz}$ at the X2C-LDA level of theory. Therefore, the PV difference $\Delta_{R S} E_{\mathrm{PV}}$ between the two enantiomers for the $0 \rightarrow 1$ fundamental transition amounts to 0.71 $\mathrm{Hz}$ at B3LYP level and $0.90 \mathrm{~Hz}$ at LDA level and is rather large. ${ }^{37}$

\section{CONCLUSIONS}

We have studied PV effects for a new set of chiral molecules containing the heavy metal tungsten at the chirality center. The $\mathrm{W}-\mathrm{N}$ stretching mode for these molecules lies conveniently in the laser frequency range. The calculated PV effects exceed those for the $\mathrm{Se}-\mathrm{O}$ stretching mode in the recently studied $\mathrm{SeOXY}$ molecules by a at least factor of $6,{ }^{36,47}$ and those for the $\mathrm{C}-\mathrm{F}$ stretching mode in CHXYZ by at least two orders of magnitude. ${ }^{32,40}$ We therefore conclude that these chiral tungsten complexes are promising candidates for the detection of PV in chiral molecules. The basic $\mathrm{N} \equiv \mathrm{WXYZ}$ structure could also be the starting point for the design of new thermodynamically stable complexes ${ }^{74}$ similar to the one already designed for the oxorhenium compounds by Crassous and co-workers. ${ }^{20}$ Moreover, these molecules should also be investigated for PV effects in other properties, e.g., in high-resolution NMR or UV spectroscopic measurements. Relativistic coupled cluster calculations are also required in future to obtain more accurate results. ${ }^{75}$ The syntheses of these chiral tungsten compounds may perhaps be the greatest challenge. However, $\mathrm{N} \equiv \mathrm{WH}_{3}$ and $\mathrm{N} \equiv \mathrm{WF}_{3}$ have been investigated spectroscopically ${ }^{38,39}$ and $\mathrm{N} \equiv \mathrm{WCl}_{3}$ is well known. ${ }^{69}$ If it turns out that the synthesis, isolation, and subsequent enantiomeric purifications on the laboratory scale are not feasible for these compounds, they could still be prepared in the gas phase, mass selected, and finally trapped at ultracold temperatures.

\section{ACKNOWLEDGMENTS}

This work was part of a French-New Zealand collaboration on PV (project NCPMOL funded by the Agence Nationale de la Recherche, ANR, France and the Marsden Project No. 06-MAU-057 funded by the Royal Society of New Zealand)

${ }^{1}$ U. J. Meierhenrich, Amino Acids and the Asymmetry of Life (Springer, Berlin, 2008).

${ }^{2}$ A. Guijarro and M. Yus, The Origin of Chirality in the Molecules of Life (RSC, Cambridge, 2009).

${ }^{3}$ F. Hund, Z. Phys. 43, 805 (1927).

${ }_{5}^{4}$ A. Amann, J. Math. Chem. 6, 1 (1991).

${ }^{5}$ J. Trost and K. Hornberger, Phys. Rev. Lett. 103, 023202 (2009).

${ }^{6}$ Y. Yamagata, J. Theor. Biol. 11, 495 (1966).

${ }^{7}$ D. W. Rein, J. Mol. Evol. 4, 15 (1974).

${ }^{8}$ E. Gajzago and G. Marx, ATOMKI Kozl. 16, 177 (1974).

${ }^{9}$ V. S. Letokhov, Phys. Lett. 53A, 275 (1975).

${ }^{10}$ O. N. Kompanets, A. R. Kukudzhanov, and V. S. Letokhov, Opt. Commun. 19, 414 (1976)

${ }^{11}$ C. Daussy, T. Marrel, A. Amy-Klein, C. T. Nguyen, C. J. Bordé, and C. Chardonnet, Phys. Rev. Lett. 83, 1554 (1999).

${ }^{12}$ A. Lahamer, S. M. Mahurin, R. N. Compton, D. House, J. K. Laerdahl, M. Lein, and P. Schwerdtfeger, Phys. Rev. Lett. 85, 4470 (2000).

${ }^{13} \mathrm{P}$. Schwerdtfeger, in Computational Spectroscopy, edited by J. Gruenenberg (Wiley, New York, 2010) (and references therein).

${ }^{14}$ E. Arimondo, P. Glorieux, and T. Oka, Opt. Commun. 23, 369 (1977).

${ }^{15}$ J. Crassous, F. Monier, J.-P. Dutasta, M. Ziskind, C. Daussy, C. Gain, and C. Chardonnet, ChemPhysChem 4, 541 (2003).

${ }^{16}$ C. Daussy, O. Lopez, A. Amy-Klein, A. Goncharov, M. Guinet, C. Chardonnet, F. Narbonneau, M. Lours, D. Chambon, S. Bize, A. Clairon, G. Santarelli, M. E. Tobar, and A. N. Luiten, Phys. Rev. Lett. 94, 203904 (2005).

${ }^{17}$ M. Schnell and G. Meijer, Angew. Chem., Int. Ed. 48, 6010 (2009); Angew. Chem. 121, 6124 (2009).

${ }^{18}$ M. Ziskind, C. Daussy, T. Marrel, and C. Chardonnet, Eur. Phys. J. D 20, 219 (2002).

${ }^{19}$ M. P. Ledbetter, C. W. Crawford, A. Pines, D. E. Wemmer, S. Knappe, J. Kitching, and D. Budker, J. Magn. Reson. 199, 25 (2009).

${ }^{20}$ F. De Montigny, R. Bast, A. S. P. Gomes, G. Pilet, N. Vanthuyne, C. Roussel, L. Guy, P. Schwerdtfeger, T. Saue, and J. Crassous, Phys. Chem. Chem. Phys. DOI:10.1039/b925050f.

${ }^{21}$ B. Darquié, C. Stoeffler, A. Shelkovnikov, C. Daussy, A. Amy-Klein, C. Chardonnet, S. Zrig, L. Guy, J. Crassous, P. Soulard, P. Asselin, T. R. Huet, P. Schwerdtfeger, R. Bast, and T. Saue, Chirality, in press.

${ }^{22}$ M. Quack, J. Stohner, and M. Willeke, Annu. Rev. Phys. Chem. 59, 741 (2008) (and references therein).

${ }^{23}$ J. Crassous, C. Chardonnet, T. Saue, and P. Schwerdtfeger, Org. Biomol. Chem. 3, 2218 (2005) (and references therein).

${ }^{24}$ F. Faglioni and P. Lazzeretti, Phys. Rev. A 67, 032101 (2003).

${ }^{25}$ M. Quack, Angew. Chem., Int. Ed. 41, 4618 (2002); Angew. Chem. 114, 4812 (2002)

${ }^{26}$ M. A. Bouchiat and C. C. Bouchiat, Phys. Lett. B 48, 111 (1974).

${ }^{27}$ J. K. Laerdahl and P. Schwerdtfeger, Phys. Rev. A 60, 4439 (1999).

${ }^{28}$ S. Nahrwold and R. Berger, J. Chem. Phys. 130, 214101 (2009).

${ }^{29}$ R. A. Hegstrom, D. W. Rein, and P. G. H. Sandars, J. Chem. Phys. 73, 2329 (1980)

${ }^{30}$ R. Bast and P. Schwerdtfeger, Phys. Rev. Lett. 91, 023001 (2003).

${ }^{31}$ P. Schwerdtfeger, J. Gierlich, and T. Bollwein, Angew. Chem., Int. Ed. 42, 1293 (2003); Angew. Chem. 115, 1331 (2003).

${ }^{32}$ J. K. Laerdahl, P. Schwerdtfeger, and H. M. Quiney, Phys. Rev. Lett. 84, $3811(2000)$

${ }^{33}$ P. Schwerdtfeger and R. Bast, J. Am. Chem. Soc. 126, 1652 (2004).

${ }^{34}$ P. Schwerdtfeger, T. Saue, J. N. P. van Stralen, and L. Visscher, Phys. Rev. A 71, 012103 (2005).

${ }^{35}$ D. Figgen, and P. Schwerdtfeger, Phys. Rev. A 78, 012511 (2008). Note that in the abstract and Table I of Ref. 35 the results for the $R$-enantiomer are given and not for the $S$-enantiomer as stated.

${ }^{36}$ D. Figgen and P. Schwerdtfeger, J. Chem. Phys. 130, 054306 (2009).

${ }^{37}$ D. Figgen, A. Koers, and P. Schwerdtfeger, Angew. Chem., Int. Ed. 49, 2941 (2010); Angew. Chem. 122, 3003 (2010).

${ }^{38} \mathrm{X}$. Wang and L. Andrews, Organometallics 27, 4885 (2008). 
${ }^{39}$ X. Wang, L. Andrews, R. Lindh, V. Veryazov, and B. O. Roos, J. Phys. Chem. A 112, 8030 (2008).

${ }^{40}$ P. Schwerdtfeger, J. K. Laerdahl, and C. Chardonnet, Phys. Rev. A 65, 042508 (2002).

${ }^{41}$ M. J. Frisch, G. W. Trucks, H. B. Schlegel et al., GAUSSIAN 03, Revision C.02, Gaussian, Inc., Wallingford, CT, 2004.

${ }^{42}$ A. D. Becke, J. Chem. Phys. 98, 5648 (1993).

${ }^{43}$ P. J. Stephens, F. J. Devlin, C. F. Chabalowski, and M. J. Frisch, J. Phys. Chem. 98, 11623 (1994)

${ }^{44}$ T. H. Dunning, Jr., J. Chem. Phys. 90, 1007 (1989).

${ }^{45}$ R. A. Kendall, T. H. Dunning, Jr., and R. J. Harrison, J. Chem. Phys. 96, 6796 (1992)

${ }^{46}$ D. E. Woon and T. H. Dunning, Jr., J. Chem. Phys. 98, 1358 (1993).

${ }^{47}$ D. Figgen, K. A. Peterson, M. Dolg, and H. Stoll, J. Chem. Phys. 130, 164108 (2009).

${ }^{48}$ K. A. Peterson, D. Figgen, E. Goll, H. Stoll, and M. Dolg, J. Chem. Phys. 119, 11113 (2003).

${ }^{49}$ P. Schwerdtfeger, T. Fischer, M. Dolg, G. Igel-Mann, A. Nicklass, H. Stoll, and A. Haaland, J. Chem. Phys. 102, 2050 (1995).

${ }^{50}$ T. Leininger, A. Nicklass, H. Stoll, M. Dolg, and P. Schwerdtfeger, J. Chem. Phys. 105, 1052 (1996).

${ }^{51}$ P. Schwerdtfeger, J. R. Brown, J. K. Laerdahl, and H. Stoll, J. Chem. Phys. 113, 7110 (2000)

${ }^{52}$ V. Barone, J. Chem. Phys. 120, 3059 (2004).

${ }^{53}$ G. Rauhut, V. Barone, and P. Schwerdtfeger, J. Chem. Phys. 125, 054308 (2006).

${ }^{54}$ A. A. Clabo, Jr., W. D. Allen, R. B. Remington, Y. Yamaguchi, and H. F. Schaefer III, Chem. Phys. 123, 187 (1988)

${ }^{55}$ V. Barone, Chem. Phys. Lett. 383, 528 (2004).

${ }^{56}$ P. Carbonniere, T. Lucca, C. Pouchan, N. Rega, and V. Barone, J. Comput. Chem. 26, 384 (2005).

${ }^{57}$ V. Barone, J. Chem. Phys. 122, 014108 (2005).
${ }^{58}$ M. Iliaš and T. Saue, J. Chem. Phys. 126, 064102 (2007).

${ }^{59}$ J. Sikkema, L. Visscher, T. Saue, and M. Iliaš, J. Chem. Phys. 131, 124116 (2009).

${ }^{60}$ B. A. Hess, C. M. Marian, U. Wahlgren, and O. Gropen, Chem. Phys. Lett. 251, 365 (1996).

${ }^{61}$ B. Schimmelpfennig, program AMFI, Stockholm, Sweden.

${ }^{62}$ DIRAC, a relativistic $a b$ initio electronic structure program, Release (DIRAC08) (2008), written by L. Visscher, H. J. Aa. Jensen, and T. Saue, with new contributions from R. Bast, S. Dubillard, K. G. Dyall, U. Ekström, E. Eliav, T. Fleig, A. S. P. Gomes, T. U. Helgaker, J. Henriksson, M. Iliaš, Ch. R. Jacob, S. Knecht, P. Norman, J. Olsen, M. Pernpointner, K. Ruud, P. Sałek, and J. Sikkema (see http://dirac.chem.sdu.dk).

${ }^{63}$ K. Fægri, Theor. Chem. Acc. 105, 252 (2001).

${ }^{64}$ S. A. Blundell, J. Sapirstein, and W. R. Johnson, Phys. Rev. D 45, 1602 (1992).

${ }^{65}$ L. Visscher and K. G. Dyall, At. Data Nucl. Data Tables 67, 207 (1997).

${ }^{66}$ J. W. Cooley, Math. Comput. 15, 363 (1961).

${ }^{67}$ B. Numerov, Publs. Obs. Central Astrophys. Russ. 2, 188 (1933).

${ }^{68}$ M. B. Smith and J. March, March's Advanced Organic Chemistry: Reactions, Mechanisms, and Structure, 5th ed. (Wiley-Interscience, Hoboken, NJ, 2001).

${ }^{69}$ K. Dehnicke and J. Strähle, Z. Anorg. Allg. Chem. 339, 171 (1965).

${ }^{70}$ K. Dehnicke and J. Strähle, Angew. Chem., Int. Ed. Engl. 20, 413 (1981).

${ }^{71}$ M. R. Close and R. E. McCarley, Inorg. Chem. 33, 4198 (1994).

${ }^{72}$ W. W. Schoeller and A. Sundermann, Inorg. Chem. 37, 3034 (1998)

${ }^{73}$ R. Bast and P. Schwerdtfeger, J. Chem. Phys. 119, 5988 (2003).

${ }^{74}$ K. Dehnicke and J. Strähle, Angew. Chem., Int. Ed. Engl. 31, 955 (1992).

${ }^{75}$ C. Thierfelder, G. Rauhut, and P. Schwerdtfeger, Phys. Rev. A 81, 032513 (2010). 